\title{
42 Logic, Ethics and the Ethics of Logic
}

... the main reason logic is unsettled is that thirteen different opinions are current as to the true aim of the science. Now this is not a logical difficulty, but an ethical difficulty; for ethics is the science of aims. Secondly, it is true that ethics has been, and always must be, a theatre of discussion for the reason that its study consists in the gradual development of a distinct recognition of a satisfactory aim. It is a science of subtleties, no doubt; but it is not logic, but the development of the ideal, which really creates and resolves the problems of ethics. (MS 431 with corrections from MS 429, 1902).

Peirce wrote this in 1902 as part of his "Minute Logic", a major book project from his later, officially unemployed, years. The editors of EPII note that the book was so named "to reflect the minute thoroughness with which [Peirce] planned to examine every relevant problem" (xiv), and that within a year it ran to hundreds of pages. This vast project gave Peirce the opportunity to think in intricate detail about the architectonic structure of his thought. This groundwork bore much fruit: notably in Peirce's 1902 grant application to the Carnegie Institution, still one of the best guides to the way Peirce's mature thought would have unfolded had he been given access to resources commensurate with his abilities, and the 1903 Harvard lectures on pragmatism where (despite struggles with James over scope and purpose) he managed to distil into seven evening lectures a new philosophical system of brilliance and power, with many outlines previously unknown in the history of philosophy.

This remarkable quote encapsulates an enormous amount of Peirce's philosophy, and offers a challenge to contemporary mainstream philosophy with respect to the codifiability of its subject matter on a number of levels, of which I will here discuss three: Peirce's views on pragmatism, ethics and logic. The last two are particularly worth discussing in this context as a new relationship between ethics and logic was first worked out properly by Peirce around this time. Thus in the "Minute Logic" he writes that he has only recently come to realize that logic is only the third of the normative sciences, being "preceded by Esthetics and Ethics" (CP 2.197). He also notes that his understanding of the nature of ethics has shifted - although for many years he "doubted very much whether it was anything more than a practical science", he is now beginning to understand the purpose of ethical theory, and to place it in "all the intimacy of its relation with Logic" (CP 2.198). (The next year, in his 5th Harvard lecture he

1 University of Waikato, Hamilton, New Zealand. 
states firmly, "Normative science is not a skill, nor is it an investigation conducted with a view to the production of skill" (CP 5.125)). He also clarifies that the scientific purpose of Ethics is not pronouncing things to be right and wrong, but understanding what rightness and wrongness are:

We are too apt to define ethics to ourselves as the science of right and wrong. That cannot be correct, for the reason that right and wrong are ethical conceptions which it is the business of that science to develop and to justify. A science cannot have for its fundamental problem to distribute objects among categories of its own creation. (CP 2.198).

Thus, for example, to define physics as, say, 'the science which measures gravitational forces' would foreclose on physicists being able to develop new and more sophisticated conceptions of that subject matter, and it would also not mean a great deal without a theory of what gravitational forces consist in, which can only be given within physics.

As is well known, Peirce's final architectonic descended as follows: mathematics, phenomenology, aesthetics, ethics, logic, and on to the special sciences, starting with metaphysics, with each level drawing 'principles' from above and 'data' from below. At the same time pragmatism unites all levels by clarifying in general what it is for a sign to mean something. In each of our three philosophical areas: pragmatism, ethics and logic, as noted, our quote raises a certain basic issue concerning the 'codifiability of knowledge'. Can all knowledge be placed in propositional form and stated explicitly? In recent times this issue has also been broached under headings such as "representationalism" (see for instance (Brandom 2011)), and "knowledge how vs. knowledge that" (Williamson and Stanley 2001). We will see how in all three philosophical areas Peirce is able to resist commitment to a simplistic codifiability via his exceptionally rich and nuanced account of the functioning of signs.

i) Pragmatism. In the quote Peirce distinguishes between 'logic' and the development of an ideal. Much subtlety in Peirce's account of signification derives from its stipulation that meaningful signs are so by virtue not just of an objectan entity to which they refer - but also an interpretant - a usage of that sign by a community in negotiating the world. Signs must affect our practice in order to signify anything at all, and in his choice to keep the interpretant independent of and irreducible to the object, Peirce signals that the usage of our signs in principle outruns that to which they may be said to refer in any given case and at any given time. Peirce does in places suggest that at some far future point interpretant and object will "crystallise" in the summum bonum, but notes that even if one were to reach that ideal terminus, all thought would there cease (CP 6.33). 
Thus in a 1908 letter to Victoria Lady Welby, Peirce wrote, "I define a Sign as anything which is so determined by something else, called its Object, and so determines an effect upon a person, which effect I call its Interpretant, that the latter is thereby mediately determined by the former". He immediately added, "My insertion of 'upon a person' is a sop to Cerberus, because I despair of making my own broader conception understood" (SS: 80-81). What is the true upshot (or 'final interpretant') of a sign within the context of pragmatism is a delicate matter to state strictly. Around 1902 Peirce was seeking to reemphasise this true upshot - from sign-users' practice, to some degree back to their referents - as a corrective against then-current readings of pragmatism (e.g. from James and his students) which to his mind overemphasised the practical. Thus in his 1901 entry on 'pragmatism' in Baldwin's Dictionary of Philosophy and Psychology, he wrote:

If it be admitted ... that action wants an end, and that that end must be something of a general description, then the spirit of the maxim itself, which is that we must look to the upshot of our concepts in order to rightly apprehend them, would direct us towards something different from practical facts, namely to general ideas, as the true interpreters of our thought. (CP 5.3).

In 1905 in "What Pragmatism Is", he spoke even more strongly on the matter:

... if pragmaticism really made Doing to be the Be-all and the End-all of life, that would be its death. For to say that we live for the mere sake of action, as action, regardless of the thought it carries out, would be to say there is no such thing as rational purport. (CP 5.429).

ii) Ethics. We noted above that Peirce draws a distinction between logic and "the development of the ideal". In the same sentence he argues that only the latter "really creates and resolves the problems of ethics". It might seem that here he is stating that practice rather than theory is paramount in working out the discipline of ethics. However the relationship between theory and practice in ethics is a notoriously thorny issue for Peirce. It is well-known that in the first of his 1898 Harvard lectures, "Philosophy and the Conduct of Life", Peirce made strong claims apparently suggesting that ethical insight should spring from instinct alone, since our reasoning is too fallible to bear the weight of real-life ethical decision-making, giving the following somewhat searing example:

[the man] who would precipitately change his code of morals at the dictate of a philosophy of ethics - who would, let us say, hastily practice incest - is a man whom we should consider unwise. The regnant system of sexual rules is an instinctive or sentimental induction summarizing the experience of all our race. That it is abstractly and absolutely infallible we do not pretend; but that it is practically infallible for the individual ... that we do maintain. (CP 1.633). 
The overall moral of this lecture was to recommend sentimentalism over 'rationalism' in ethics, and to claim that ethical theory develops solely by "slow percolation" of rational ideas into instinct over the ages, rather than by conscious or explicit inquiry. However by 1902 Peirce seems to have softened on the desirability of conscious ethical theorising.

The codifiability of ethics is generally so taken for granted in contemporary mainstream philosophy that it is not thought even to need arguing for. Thus for instance The Stanford Encyclopedia of Philosophy defines the current 'top two' ethical theories as follows: “... deontology is one of those kinds of normative theories regarding which choices are morally required, forbidden, or permitted. In other words, deontology falls within the domain of moral theories that guide and assess our choices of what we ought to do ... And within that domain, deontologists ... stand in opposition to consequentialists”. (Alexander and Moore 2012, see also Walter Sinnott-Armstrong 2011). There is, however, a valiant rear-guard critique of codifiability from the field's current 'third party': virtue ethics. Thus Rosalind Hursthouse (nicely) summarises the codifiability claim as follows:

... the task of ethical theory is "to come up with a code consisting of universal rules or principles ... which would have two significant features: (a) the rule(s) would amount to a decision procedure for determining what the right action was in any particular case; (b) the rule(s) would be stated in such terms that any non-virtuous person could understand and apply it (them) correctly. (Hursthouse 2012).

Hursthouse suggests that the problem with this is that any application of such a code purely on its own terms generally has awful results (as Peirce predicted in 1898), and that this in fact happened with the growth of professionalised applied ethics through the 1960s and 70s, where:

[m]ore and more utilitarians and deontologists found themselves agreed on their general rules but on opposite sides of the controversial moral issues in contemporary discussion. It came to be recognised that moral sensitivity, perception, imagination, and judgement informed by experience - phronesis in short - is needed to apply rules or principles correctly. (Hursthouse 2012).

However many consequentialists and deontologists - undaunted by this critique currently dismiss virtue ethics for not being "action-guiding” (i.e. codifiable) (e.g. Das 2003), while other virtue ethicists endeavour to demonstrate that their view is action-guiding (van Zyl 2009; Swanton 2001).2

2 It is also worth mentioning here that contemporary critique of ethical codifiability is also coming from moral particularists such as Jonathan Dancy. 
Peirce's discussion of ethics places this debate in a broader context which arguably points the way towards resolution. Firstly, as already noted, Peirce suggests that ethics should not be understood as a discipline whose role is to (as the Stanford Encyclopedia put it) "assess and guide our choices" as right or wrong since (as we saw Peirce put it) "these concepts are not prior to the discipline of ethics but emerge from it”. In other words, before making definitive pronouncements concerning which acts are good and bad one needs to answer the question of what goodness and badness are, and Peirce suggests that the latter question is so deep as to have been barely broached by philosophy to his day. (In this regard he notes, interestingly, that the normative character of Ethics, far from being provided by the practical application of Ethics, "may equally have its origin in the circumstance that the science which presents it is so very abstract, so alien to any experiential lineage, that ideals alone, in place of positive facts of experience, can be its proper objects" (CP 2.46). In Lecture 6, Peirce precisely offers consequentialism (or 'vulgar utilitarianism') as an example of the problems caused by rushing to answer the former question at the expense of the latter. He claims that such utilitarianism is unable to explain why its pronouncements concerning right and wrong should be considered true:

... [the utilitarian's] fault does not lie in his pressing too much the question of what would be the good of this or that. On the contrary, his fault is that he never presses the question half far enough, or rather he never really raises the question at all. He simply rests in his present desires as if desire were beyond all dialectic. He wants, perhaps, to go to heaven. But he forgets to ask what would be the good of his going to heaven. He would be happy there, he thinks. But that is a mere word. It is no real answer to the question. (CP 5.158).

Secondly, Peirce's pragmatism shows how codifiable theory and uncodifiable practice can work together over time, serving as different faces of the same semiotic coin, since "our logically controlled thoughts compose a small part of the mind, the mere blossom of a vast complexus which we may call the instinctive mind" (CP 5.212). Thus, the never-fully-codifiable acting of individuals in situations which lead to open-ended sets of experiences and feelings gives ethical concepts meaning and a spur to future development in ethical inquiry. Meanwhile, however, the codification of ethical theory greatly strengthens and organises that inquiry. Rather than opposing positions of 'representationalism' and 'antirepresentationalism', then, we have necessary complements in an integrated process which we must hope (like the whist-player who does not know that player card distribution allows tricks to be saved, but must hope that it does in order to have any chance of winning (CP 2.113)) over the long-run arcs towards truth. This temporal-evolutionary dimension to theorising which is opened up 
by Peirce's theory of truth is a strength today arguably largely unappreciated outside of Peirce scholarship.

iii) Logic. In the opening paragraphs of the "Minute Logic", Peirce announces that logic is "the theory of the conditions which determine reasonings to be secure" (CP 2.1). This reveals an understanding of the discipline considerably broader than that generally found today. In particular, it does not just embrace formal logic, but also philosophy of science, epistemology, and theory of cognition. As Moore helpfully summarises the matter in its relationship to ethics, "logic is concerned with the criticism of a certain kind of conduct (namely reasoning)" (Moore 2010: 23).

In the "Minute Logic" Peirce not only places the discipline of logic within a wider architectonic but also sets out a systematic account of its different branches, and clarifies its purpose. The "thirteen different opinions ... as to the true aim of the science" cited in the quote are no mere figure of speech. In the section published in CP 2.18-78 (entitled there "Different Methods in Logic") Peirce considers in turn the desirability of basing logical principles upon: i) a certain logical 'feeling', ii) an individual experience, iii) the inner light of reason, iv) metaphysics, v) the results of scientific psychology, vi) the data of psychology, vii) a basic science underlying all sciences, which the Germans call Wissenschaftslehre, and to which nowadays the term 'epistemology' arguably at least approaches, viii) a kind of ordinary language philosophy which studies grammatical structures, ix) what will tend towards the stability of society, $\mathrm{x}$ ) church authority, xi) the history of science, xii) everyday experience, and finally, xiii) the same source as mathematical truth, which “... is derived from observation of creations of our own visual imagination, which we may set down on paper in form of diagrams".

Peirce sees the thirteenth answer as the right one, and he goes on to chart the stages he sees as required to develop it. First he outlines his philosophical categories, here termed 'originality', 'obsistence' and 'transuasion'. These are used to derive, respectively, the concepts of sign, object and interpretant, then the trichotomous distinction between kinds of sign: icon, index and symbol. Following this, Peirce draws a further functional distinction between sign-types: term, proposition and argument. Having derived the concept of an argument, he distinguishes the three argument forms: abduction, deduction, induction, and argues that there are only three. The question of the validity of induction leads to probability theory, which leads on to the logic of the natural sciences. In the 1903 Harvard lectures this outline is considerably more compressed and Peirce bemoans the fact that he can offer no real arguments, but merely state some of 
the chief conclusions to which he has been led. However the same essential stages are visible, although he also emphasises the founding of logic in a direct perception of Thirdness which blurs the line between structured inference and felt "continuous process" (CP 5.181) in the way that a set of drawn circles can be seen as a stone wall and then as a mere set of drawn circles again, and there is no clear division between the two seeings, which he was newly struck by.

In this mature Peircean program for the development of logic at least two ethical dimensions are worth noting. Firstly, it follows from the role of the everevolving interpretant in sign-development that logic is essentially a social enterprise directed at a future goal that no-one can enjoy individually. But Peirce was saying this sort of thing from the start of his career (e.g. in "The Fixation of Belief"). What is arguably new in this 1902-3 period is an emphasis on the fact that logic rests on a dyadic distinction between truth and falsity, and that this is a special case of the dyadic distinction between rightness and wrongness found in ethics. Moreover, the key to keeping the two poles separate - in ethical behaviour, and thus also in logic - is self-control. These insights are worked out in Peirce's criticisms of Dewey's volume Studies in Logical Theory, in a letter written in 1905, where he writes, "I find the whole volume penetrated with this spirit of intellectual licentiousness, that does not see that anything is so very false ...", and:

Chicago hasn't the reputation of being a moral place; but I should think that the effect of living there ... would be to make you feel all the more the necessity for Dyadic distinctions, - Right and Wrong, Truth and Falsity. These are only to be kept up by self control. Now just as Moral Conduct is Self-controlled conduct so Logical Thought is Moral, or Selfcontrolled, thought. (CP 8.240-1).

iv) The development of the ideal. Bringing together these considerations concerning ethics and logic, we now consider the nature of the development of the (logical) ideal. What would such an enterprise actually consist in? We can now see that it must consist in a community of inquiry not merely theorizing about or codifying its aim of truth, but actively practicing the pursuit of it, communally, exercising self-control to avoid spending the community of inquiry's resources on activities that are not conducive to that pursuit. Insofar as such practices succeed they will embody (if only in some small way) the growth of concrete reasonableness which Peirce identified in his later work as the summum bonum incarnate.

Given that, one might speculate in a critical vein on current institutional arrangements in academia. There has arguably been a significant shift in recent years to exert pressure on professional inquirers to spend as much of their work life as possible producing 'research outputs' (including, even, research outputs 
1 about truth), to the extent that many academics now lack the time to perform 2 other community-building but output-free (uncodified) activities, such as read3 ing others' work, and training and supporting the young. Insofar as this is the 4 case, from a Peircean perspective this 'logical ideal' may be seen as unethical. 5 What would it mean if we really loved the logic in each other?

6

\section{Acknowledgements}

In the writing of this piece I am indebted to extensive conversations about Peirce's ethics of inquiry with Joshua Black. 